\title{
A STUDY OF RICKETS; Incidence in London.
}

\author{
BY \\ DONALD PATERSON, M.B. (Edin.), M.R.C.P. (London), \\ AND \\ RUTH DARBY, M.B., Ch.B. (Birm.). \\ (From the Infants' Hospital, Westminster.)
}

In order to ascertain the incidence of rickets in London a study was attempted during the months of February, March and April of 1925.

It was thought that these being the darkest months of the year, following on a long, sunless period, the incidence of rickets would be at its height.

Our first difficulty was to define the basis upon which rickets could be diagnosed. We had over and over again diagnosed rickets clinically because of a bossed skull, enlargement of ends of long bones and beaded ribs, only to find by X-ray that the rickets was completely healed. Clinically, therefore, it would only appear possible to diagnose that the child had had rickets, and it appeared impossible to us to diagnose the presence of active rickets with any degree of certainty by clinical methods. Since it was active rickets in which we were interested we were driven to study our cases with the radiographer, and X-rays of the wrists were taken in every case by Dr. Bertram Shires.

In all some 339 new cases were radiographed. The children's ages ranged from a few weeks to two years. This figure represents the total number of children of that age seeking advice at the Infants' Hospital and at St. Thomas' Hospital during that period.

Number of Cases of Active Rickets.

Out of 339 cases :-

4 showed active radiographic rickets-that is $1.2 \%$ of the total;

110 showed slight or gross signs of rickets clinically, but proved healed radiographically-that is $32 \%$ of the total;

225 appeared normal clinically and radiographically-that is $67 \%$ of the total were normal.

The Relationship between Cod-liver ()il and Rickets.

Probably the most surprising point elicited by this investigation was the fact that out of the 339 cases, 313 or $92 \%$ had been having some cod-liver oil preparation for a considerable period. That such a high percentage of the infants of the poor are receiving cod-liver oil should be a gratifying fact to those interested in public welfare. That these infants had been protected from rickets by this antirachitic medication there would seem to be very little doubt. None of the four cases of acute rickets had had col-liver oil.

Of the 110 clinical rickets which were healed, 96 or $88 \%$ had had codliver oil. It is, therefore, safe to assume that the oil brought about healing in the darkest months of the year. 
Of the 225 cases showing no clinical rickets, 216 or $96 \%$ had had cod-liver oil, and of the remaining nine cases five were entirely breast fecl, one was partly breast fed and three had been entirely breast fed until just prior to the investigation.

\section{Relationship between Diet and Rickets.}

Of the four cases of active rickets, three were having whole full cream dried milk and since they were over a year old their cliet was mixed consisting of cereals, gravy and potato; the fourth case had had cow's milk and cereals.

Of the 110 showing clinical rickets :-

36 or $33 \%$ had dried milk ;

23 or $20 \%$ had sweetened condensed milk;

40 or $37 \%$ had cow's milk;

11 or $10 \%$ were on the breast.

The diets of those cases not showing clinical rickets were made up in much the same proportions :-

71 or $31 \%$ had dried milk;

29 or $13 \%$ had sweetened condensed milk;

79 or $35 \%$ had cow's milk;

46 or $21 \%$ had breast milk.

These figures suggest that despite the variety of diets as shown above the addition of cocl-liver oil protects against rickets.

Relationship between Poverty and Rickets.

Does this relationship exist?

Does an infant develop rickets more radily in those homes which are poorest? Our statistics show the following :-

One case of active rickets came from a family consisting of parents and three children where the income was $£, 5$ per week.

Two cases of active rickets came from families where there were more than three children and the total earnings were $£ 2$ 10s. Od. per week.

The fourth case of active rickets came from a family where there were seven children with an income of $£ 310 \mathrm{~s}$. Od. per week.

These figures are too small to reach any conclusions of value, but it may be readily seen that in three of the four cases the families were poor.

\section{Relationship between Weight and Rickets.}

Of the 339 cases :-

45 or $13 \%$ were average weight ;

10 or $3 \%$ were overweight;

284 or $84 \%$ were underweight ;

The 4 acute rickets were all underweight.

Of the 110 clinical rickets :-

16 or $15 \%$ were average weight ;

4 or $3 \%$ were overweight ;

90 or $82 \%$ were underweight.

These figures show that the majority of the cases investigated were underweight. This series is too small from which to draw any conclusions of real value, but they seem to suggest that there is a relation between rickets and underweight. 


\section{Relationship between Dentition and Rickets.}

Of the 110 clinical rickets :-

One-third were under the age of six months and therefore could not be expected to have teeth;

And of the remaining two-thirds 44 or $63 \%$ showed delayed dentition calculated by text-book standards.

Of the four acute rickets, all showed grossly delayed dentition.

Of the remaining 225 not showing clinical rickets 71 were under six months, and of the 154 others, 81 or $53 \%$ showed delayed dentition when calculated in the same manner.

These figures suggest that if delayed dentition be due to rickets then a large proportion of our cases which appeared clinically and radiographically free from this condition must nevertheless have suffered from it. The alternative is that our standards for estimating the dentition of children of this class must be altered.

\section{Conclusions.}

1. In a series of 339 cases between birth and two years, there were four cases of active $\mathrm{X}$-ray rickets-this is $1.2 \%$ of the total. Active rickets would appear to be uncommon at least in certain areas in London.

2. One hundred and ten cases showed clinical rickets which were proved to be healed, showing that $32 \%$ of our series had had rickets.

3. Ninety-two per cent. of the total series were having some cod-liver oil preparation.

4. Evidence is produced which suggests that cod-liver oil protected some from rickets, and healed rickets in other cases.

5. The diet of the normal cases showed that three-tenths were fed on dried milk, four-tenths on cow's milk, one-tenth on sweetened condensed milk and two-tenths on breast milk. Ninety-six per cent. of these however were having cod-liver oil, and the $4 \%$ remaining were breast fed.

6. According to modern standards $63 \%$ of cases with healed rickets and $53 \%$ of those cases not showing rickets clinically or radiographically had delayed dentition. This suggests to us that the average child of this class does not cut its first tooth at six months and new standards must be evolved for judging the state of dentition in hospital patients.

We must thank Dr. Bertram Shires for giving his time and help and enabling us to obtain the X-rays, and to the Medical Research Council we owe our thanks for the grant which covered the expenses involved in this investigation. 